\title{
EXISTENCE OF BOUNDED SOLUTIONS FOR A CLASS OF NONLINEAR FOURTH-ORDER EQUATIONS
}

\author{
MichaIL V. VOITOVICH
}

Abstract. In this article, we consider a class of nonlinear elliptic fourth-order equations with the principal part satisfying a strengthened coercivity condition. It is supposed that the lowerorder term of the equations admits an arbitrary growth with respect to unknown function and the growth rates of derivatives of this function coinciding with the exponents of the corresponding energy space. We prove a theorem on existence of bounded generalized solutions of the Dirichlet problem for equations of the given class.

Mathematics subject classification (2010): 35B65, 35J40, 35J62.

Keywords and phrases: Dirichlet problem, existence, bounded solutions, nonlinear elliptic fourthorder equations, strengthened coercivity.

\section{REFERENCES}

[1] A. Bensoussan, L. BocCardo and F. Murat, On a nonlinear partial differential equation having natural growth terms and unbounded solution, Ann. Inst. H. Poincaré Anal. Non Linéaire, 5, 4 (1988), 347-364.

[2] L. Boccardo, F. Murat And J.-P. Puel, $L^{\infty}$-estimate for some nonlinear elliptic partial differential equations and application to an existence result, SIAM J. Math. Anal., 23, 2 (1992), 326-333.

[3] P. DRÁBEK AND F. NiCOLOSI, Existence of bounded solutions for some degenerated quasilinear elliptic equations, Ann. Mat. Pura Appl., 165, 4 (1993), 217-238.

[4] D. Gilbarg And N. S. Trudinger, Elliptic Partial Differential Equations of Second Order, Springer-Verlag, Berlin, 1983.

[5] D. Kinderlehrer and G. Stampacchia, An Introduction to Variational Inequalities and Their Applications, Academic Press, New York-London, 1980.

[6] A. A. KovaleVs KiI, Entropy solutions of the Dirichlet problem for a class of fourth-order nonlinear elliptic equations with $L^{1}$-right-hand sides, Izv. Math., 65, 2 (2001), 231-283.

[7] A. A. KovaleVsKiI, On the covergence of functions in a Sobolev space satisfying special integral estimates, Ukrainian Math. J., 58, 2 (2006), 189-205.

[8] A. A. Kovalevs Ky, Nonlinear fourth-order equations with a strengthened ellipticity and $L^{1}$-data, On the notions of solution to nonlinear elliptic problems: results and developments, Quaderni di Matematica, 23, Aracne, Rome, (2009), 283-338.

[9] A. Kovalevs Ky AND F. Nicolosi, Boundedness of solutions of variational inequalities with nonlinear degenerated elliptic operators of high order, Appl. Anal., 65 (1997), 225-249.

[10] A. KovaleVSKY AND F. NiCOLOSI, On Hölder continuity of solutions of equations and variational inequalities with degenerate nonlinear elliptic high order operators, Problemi attuali dellánalisi e della fisica matematica, Aracne Editrice, Roma, (2000), 205-220.

[11] A. KovaleVs KY AND F. Nicolosi, Existence and regularity of solutions to a system of degenerate nonlinear fourth-order equations, Nonlinear Anal., 61, 3 (2005), 281-307.

[12] A. A. Kovalevs KiI AND M. V. Voitovich, On increasing the summability of generalized solutions of the Dirichlet problem for fourth-order nonlinear equations with strengthened ellipticity, Ukrainian Math. J., 58, 11 (2006), 1717-1733.

[13] O. A. LAdyZhenskaya AND N. N. URAL'TSEVA, Lineinye $i$ kvazilineinye uravneniya ellipticheskogo tipa, (Russian), Nauka, Moscow, 1973. 
[14] J.-L. Lions, Quelques méthodes de résolution des problèmes aux limites non linéaires, (French), Dunod; Gauthier-Villars, Paris, 1969.

[15] J. MOSER, A new proof of De Giorgi's theorem concerning the regularity problem for elliptic differential equations, Comm. Pure Appl. Math., 13 (1960), 457-468.

[16] F. NICOLOSI AND I. V. SKRYPNIK, Nirenberg-Gagliardo interpolation inequality and regularity of solutions of nonlinear higher order equations, Topol. Methods Nonlinear Anal., 7, 2 (1996), 327-347.

[17] L. Nirenberg, On elliptic partial differential equations, Ann. Scuola Norm. Sup. Pisa, 13, 3 (1959), $115-162$.

[18] I. V. SKRYPNIK, Higher order quasilinear elliptic equations with continouos generalized solutions, (Russian), Differentsialnye Uravneniya, 14, 6 (1978), 1104-1118.

[19] G. Stampacchia, Régularisation des solutions de problèmes aux limites elliptiques à données discontinues, Proc. Internat. Sympos. Linear Spaces (Jerusalem, 1960), Pergamon, Oxford, (1961), 399408.

[20] G. Stampacchia, Equations elliptiques du second ordre à coefficients discontinus, Séminaire de Mathématiques Supérieures, No. 16 (Été, 1965), Les Presses de l' Université Montréal, Montreal, Que. 1966.

[21] M. V. Voitovich, Integrability properties of generalized solutions of the Dirichlet problem for higher-order nonlinear equations with strengthened ellipticity, (Russian), Tr. Inst. Prikl. Mat. Mekh., 15, (2007), 3-14. 